\title{
REENCUENTRO CON SARTRE
}

\author{
Ignacio Sotelo \\ (Universtdad Libre de Berlin)
}

En este artículo, el autor nos ofrece una relectura de su propia biografía generacional resaltando el papel fundamental de la figura de Sartre. Se trata, pues, de señalar la importancia de un autor tecientemente fallecido que «en nuestros dfas ocupa una posición muy distinta de la que tuvo en los años cincuenta [y que ha] dejado de ser texto inmediato de reflexión, para convertirse en parte del contexto». En definitiva, se nos ofrece una serie de reflexiones sobre un autor de crucial importancia que Sotelo califica de «el Voltaire de nuestro siglo». 
Años de distanciamiento. El último libro de Sartre, El idiota de la familia, permaneció meses sobre la mesa antes de que tomara la decisión, casi heroica, de hincarle el diente: entretanto ya había salido el tercer y último volumen, dejando, como de costumbre, la obra inacabada. De alguna manera presentíamos que el provecho esperado no estaba en relación con el esfuerzo exigido, que otta vez se prometía mucho más de lo que el autor, de que cualquier autor, pudiera dar. Evidentemente, Sartre ya no desper. taba la fascinación que había levantado en nuestra juventud. No es simple cuestión personal: Sartre en nuestros días ocupa una posición muy distinta de la que tuvo en los años cincuenta. Antes, un libro suyo lo recibíamos con la esperanza de una revelación -con qué temblor e impaciencia acogimos, en 1960, La crítica de la razón dialéctica-; doce, trece años más tarde, un nuevo libro de Sartre era eso, «un nuevo libro de Sartte», que nos atrevíamos a comentar, incluso antes de haberlo leído. Nuestros intereses y preocupaciones matchaban por otras vías. Sartre había desaparecido de nuestra vista, tal vez por formar ya parte de nuestro horizonte; había dejado de ser texto inmediato de reflexión para convertirse en parte del contexto; no ya meta, objetivo, sino punto de partida. Sartre había quedado a nuestra espalda, lo cargamos a cuestas, lo arrastrábamos, pero de cara nos crispaba los nervios. Así las cosas, llegó la noticia de su muerte.

¿Qué significa la muerte de una persona con la que no hemos intercambiado una sola palabra, que no hemos visto ni siquiera de lejos, pero que, en una determinada época de nuestra vida, hemos dedicado muchas horas a la lectura de sus libros? ¿En qué se diferencia la relación que hayamos podido tener con Sartre, nuestro contemporáneo, de la que tenemos con otros escritores y filósofos, ya desaparecidos cuando nacimos? Sartre fue siempre para mi un personaje de la historia literaria, con el que únicamente cabe comunicat a través del papel impreso. Se lee lo escrito por él, o lo escrito sobre él, pero a nadie se le ocurre ponerse a charlar con una lámina de un libro. La sola diferencia entre una figura literaria viva y otra muerta consiste en que de la primeta aún cabe esperar alguna obra 
interesante. Pero ya ciego, incapaz de escribir, Sartre no era más que la envoltura corporal de un personaje literario fenecido. La noticia de su muerte no nos inmutó en exceso: vivía ya en la leyenda, cuando oí su nombre por vez primera a comienzos de los cincuenta; hoy continúa vivo en el mismo olimpo. El hecho de su muerte nos facilita la ocasión de que hablemos de él. (Muertes y centenarios regulan las relaciones de la opinión pública con sus hombres ilustres.) Aprovechemos la oportunidad para recapitular lo que ha significado Sartre para nosotros.

En cierto modo, a mi generación, la del 56, bien pudiera llamársele sartriana: cuando cumplimos los veinte, Sartre era la estrella que brilliba en el firmamento literario y filosófco. Las vivencias infantiles configuran el carácter; las lecturas juveniles, la visión del mundo. Los que a la sázón ya eran cuarentones leyeron a Sartre protegidos por otras experiencias y lecturas. Nosotros, en cambio, lo tecibimos a pecho descubierto y con el afán juvenil de identificación. El discurso sartriano constituyó el modo de enfrentarnos con el «enigma de la existencia», una vez desprendidos de las creencias impuestas o heredadas. Importa tener en cuenta de donde veníamos -..la España de la postguerra- para poder ponderar lo abismal del salto, el riesgo de la empresa.

No dejaría de tener su atractivo un estudio sobre las circunstancias en que llegamos a Sartre los españoles de mi generación. La información que manejábamos provenía del zumor: semejaba el siseo de una conversación sobre el sexo en un colegio de monjas. Lo más vulgar y lo más nobie podían confundirse en la misma atracción por lo prohibido. Despertada la curiosidad, había que vencer no pocos obstáculos, compra clandestina del libro y préstamo secreto entre amigos. A las dificultades externas se unían las propias del texto: relataba, es verdad, experiencias profundamente sentidas -la literatura del absurdo tenía algo de español genérico, muy en particular en aquellos añosm, pero expresadas en un lenguaje por completo extraño, sin la menor vinculación con las palabras aprendidas. El adjetivo que más aforaba a nuestros labios - ¿verdad, Jaime Maestro? - era kafkiano: kafkiana resultaba la clase obligatoria de religión, como la conversación con nuestros padres, la arenga de turno o la discusión en la calle a altas hotas de la madrugada. La metamorfosis y La náusea nos parecían obras gemelas, que mostraban distintas reacciones posibles ante un mismo mundo, el de nuestra cotidianeidad madrileña, una vez arrojados al infierno de la adolescencia.

En mi caso, un destino, que diríamos inflexible, me acercó a Sartre. Alumno del Liceo Francés, la cultura francesa se había convertido en atalaya 
privilegiada para contemplar la realidad. Pasé el vetano de 1951, recién cumplidos los quince, en Paŕs, asistiendo a los cursos de «lengua y civilización francesas» que, para extranjeros, ofrecía la Sorbona. Camus y Sartre eran las vedettes, lo mejor que podía lucir Francia, que entonces equivalía para mí al mundo. Regresé a Madrid barajando «absurdo» y «existencia» con «subjetividad» y «revuelta»; pero no existencialista, me repugnan las modas, sino nietzscheano. Gracias a la indicación de un compañero alemán, en aquel verano parisino mi gran revelación se llamó Federico Nietzsche, que leí en traducciones francesas. Más tarde supe que también Sartre había pasado en su juventud por la fiebre nietzscheana -en su primera obra está bien patente- $y$ que, por tanto, antes que en Sartre me adentré en sus orígenes. Justamente esta primera infidelidad a Francia, subyugado por lo germánico, constituyó el elemento que años más tarde más estrechamente me iba a ligar a Sartre, el pensador francés de más clara y recia prosapia alemana.

En octubre de 1953 entré, no sin algunas expectativas, en el caserón de San Bernardo. La universidad española logró expulsarme nada más puestos los pies en su recinto: ni lo que se decía ni cómo se decía tenía lo más mínimo que ver con lo que realmente me interesaba. Consciente desde el primer día de que mi porvenir no se cifraba en la oposición ganada, le di solemnemente la espalda, sin haber vueito desde extonces a saber de su existencia. Prueba de que se trata de un fantasma irreal, es que pude muy bien abandonarla, dedicarme por entero a otros menesteres, y habiendo acudido a los exámenes de rigor, encontrarme con dos títulos en el bolsillo que, fantasmagóricos como son, tampoco me valieron de nada.

Me eduqué en la tertulia del Café Gijón, con tan abigarrados maestros como José María Ruiz Gallardón, Víctor Ptadera, Antonio Buero Vallejo, Pepe Suárez Carreño y, sobre todo, en la conspiración política: al escapat de la universidad como gato escaldado, una sola idea tenf́a clara, que de nada serviría la dedicación a la propia labor intelectual, mientras no hubiésemos recobrado la libertad. Subsistir simplemente como hombre significaba concentrar todas las fuetzas en el empeño inútil de levantar la losa que nos oprimía. Faltos de libertad, todas las demás metas parecen absurdas. Recuerdo una tarde en casa de Dionisio Ridruejo - - mi mentor políticotratando de convencerle de que mientras no hubiésemos derrocado a Fran-

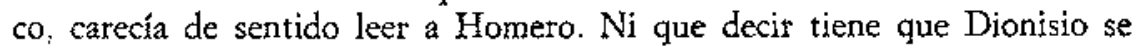
esforzaba, sin ningún éxito, en librarme de tan craso error. Lo terrible de la falta de libertad es que concentra la multiplicidad infinita de lo humano en un solo fin: recobrar la libertad perdida.

Un tema preciso, cómo acabar con la dictadura; otro de intrincada complejidad teórica, qué orden social y político tendríamos que establecer 
después de derrumbado el régimen. La tentación de admirar todo lo que condenaba la retótica oficial nos había transmitido una noción excesivamente idealizada de la Segunda República: cualquier matización crítica nos aproximaba demasiado al franquismo. La historia de España se había decidido en 1936: nacidos demasiado tarde para haber participado en la lucha, no nos quedaba más que sufrir las consecuencias. Ni recuerdos teníamos de una España sin Franco. La pregunta precisa tenía también una respuesta nítida: organizarse políticamente para participar activamente en la lucha de liberación de nuestro pueblo. Pero sólo resuelta la intrincada cuestión del poder político deseable, podíamos decidir en qué organización convendría afiliarse. Lo que nunca pasó por nuestras mentes es que el deber propio del intelectual consistiría en navegar por encima de la política o resistirse a cualquier tipo de afiliación en nombre de la libertad.

Algunos de mis compañeros, una vez dispuestos a luchar contra la dictadura, ingresaron sin más en el Partido Comunista, al que el régimen había dado una posición privilegiada, elevándolo a la categoría de su propia antítesis: si Franco era el conjunto de todos los bienes, sin mezcla de mal alguno, los comunistas reunían todos los males, sin bien alguno. Claro está que este tipo de simplificaciones admiten también una lectura inversa: si se caía en la cuenta de que el franquismo pudiera ser el conjunto de todos los males, su antítesis fácilmente se podía confundit con la tierra de promisión. Me pregunto: ¿por qué no entré en el Partido Comunista, a pesar de que no me faltó el diligente apostolado de Enrique Múgica? En este punto engatzamos de nuevo con nuestro tema.

Sería falso, además de pretencioso, decir que mi prevención frente a los comunistas se debió exclusivamente a la influencia directa de Sartre, pero la campaña de insultos, calumnias y verdades a medias que desencadenaron los comunistas contra el filósofo existencialista, que seguí con cierto interés, tuvo para mí efectos muy clarificadores. Por lo pronto, frente a mis amigos comunistas no me sentía el antediluviano o el cobarde, incapaz o temeroso, de sacar las conclusiones pertinentes, sellando mi destino con el de la clase obrera, sino que los argumentos sartrianos, que repercutían en lo más profundo de mi ser como moneda de ley, me ayudaban a asumir su desprecio con sereno distanciamiento. El pensamiento político que iba enhebrando en aquellos años se encuentra expuesto en los Entretiens sur la politique (1949), que mantuvieron Sartre. David Rousset i Gérard Rosenthal. Frente al capitalismo y el comunismo, la «tercera vía» de un socialismo cuyo objetivo fuese la realización de la libertad, to que exige «la democracia como medio y como fin de la emancipación», democracia que no es concebible sin «la liquidación de la estructura social capitalista» (p. 40). Desconfianza ante los partidos políticos tradicionales, comunistas o 
socialistas, enrollados en su propia degeneración burocrática. Crítica furibunda del estalinismo y desenmascaramiento de la Unión Soviética como un Estado que nada tendría que ver con el socialismo. Empeño de lograr una izquierda que hubiera sobrepasado el dilema marxismono marxismo, integrando en una misma tarea de lucha por la democracia real a marxistas y no marxistas.

El trauma de la guerra convierte al nietzscheano Sartre en un escritor comprometido, dispuesto a vincular su ontología de la libertad con el proyecto socialista. La ocupación alemana pone trágicamente de manifiesto que, si la sociedad está encadenada, no existe destino individual libre. La libertad del otro se revela requisito imprescindible de mi propia libertad. El infierno es el otro, pero también el supuesto de mi propia libertad. No va a resultar fácil hacer compatibles las dos aseveraciones que contiene esta frase. Imposible eliminar cualquiera de sus términos, peto tampoco vincularlos de manera convincente. Aquí tocamos fondo. Todo pensamiento llevado a su límite se tevela una contradicción. Unicamente queda clato que no cabe abstraer al individuo de su contexto social: la realidad fundamentante ya no es la "conciencia», sino la "Historia». La filosofía de Sartre, que en sus orígenes parecía que no tenía nada que ver con la política, alcanza así la dimensión política que caracteriza a toda gran filosofía. Hasta su muerte, el tema central alrededor del cual gira todo su pensamiento, consiste, justamente, en relacionar, hasta terminar por identificarlos, libertad y socialismo. «El socialismo no es una certeza, es un valor: es la libertad tomándose ella misma por fin.» (Situations 10 [1976], p. 218.)

En 1952, llega la bomba de Los comunistas y la paz. Sartre se convierte al marxismo, sin asumir por ello la filosofía de los comunistas - difícil de tragar el «materialismo dialéctico», el «diamat» que predican los estalinistas--, peto aceptando plenamente su política. Desaparece de tepente la compleja problemática planteada después de la guerra, nada de «terceras vías», nada de cuestiones éticas, de subjetividad, contingencia y otras zarandajas. Sartre se refugia radiante en el dogma recién descubierto. Con la luz de la fe resulta evidente, primero, que la clase obrera es intrínsecamente revolucionaria, que su destino histórico es el socialismo; segundo, que el Partido Comunista, pese a sus deficiencias, es el partido de la clase obrera. Ergo, no hay salvación fuera del partido. Urge, por tanto, superar el pasado de intelectual pequeñoburgués, realizando un "nuevo tipo de intelectual» que asume las responsabilidades políticas que le competen.

Con los años, Sartre va ratificándose en esta fe marxista. El escribir, la literatura, como expresión de lo absoluto $-\mathrm{y}$ sin esta creencia, ¿cómo consagrarle una vida?-, no sería más que la forma concreta que tomó su neurosis infantil en un medio familiar pequeñoburgués. Al tema ha dedi- 
cado su libro más hermoso, Las palabras (1964), llegando a obsesión en el tal vez más pretencioso y anodino, El idiota de la familia (1971-1972). Si su "constifución» neurótico-familiar, si el modo de su instalación social lo lleva inexorablemente a escribir, su vocación de hombre libre, que ha tomado conciencia de la explotación del hombre por el hombre, es la del militante. Pata combatir la opresión, la dominación de una clase, de poco sirven las palabras, ni las más hermosas ni las más directamente acusatorias. $\mathrm{El}$ instrumento propio para combatir la explotación es la acción política, la acción revolucionaria. En un orden social fundado sobre el poder de unos pocos, vale tan sólo la violencia revolucionaria. Las palabras son excrementos que expulsa el pequefioburgués, maniatado pata la acción por sus propias contradicciones. Al final, el pensamiento auténtico se transciende en acción; el flósofo se convierte en militante.

En 1952, Sartre renace como el militante perfecto, a la búsqueda del partido digno de su militancia. El levantamiento de Budapest, en 1956, impide que fructifique su luna de miel con los comunistas. A pesar del celo revolucionatio propio del converso, o más bien, precisamente por eso, la unión se muestra en seguida inviable. $Y$ no principalmente porque hubiera implicado una renuncia completa de su libertad intelectual: los comunistas exigen, además de la confesión marxista, que Sartre ya había hecho pública, la aceptación de una determinada interpretación del marxismo, el leninismo, puesta cada día a punto según los intereses cambiantes de la Unión Soviética. Sartre hubiera ido muy lejos en la humillación de su espíritu, si hubiera constituido tealmente la contrapartida de una acción revolucionaria de verdad. Pero los comunistas piden la aceptación plena del dogma para justificar como revolucionaria una política obviamente no revolucionaria, y en ocasiones incluso contrarrevolucionaria. Mayo del 68 , le abre por fin la posibilidad concreta de militar en un grupúsculo marxista-leninista, que no pidiéndole ningún acto de fe $\rightarrow$ Sartre advierte que no es maósta- le ofrece la oportunidad de extender la militancia a la discusión de acciones que se reputan revolucionarias.

Esta "conversión» tardía al marxismo, a la clase obrera, a la tevolución proletaria, retrotrae a Sartre a los planteamientos políticos de la periferia europea a finales de siglo. Muy alto es el precio que tuvo que pagar por una adolescencia libresca, ensimismada en el absoluto de su propio yo. Cuando un día se derrumba la egolatría juvenil, que en Sartre ha sido especialmente larga y creadora, prolonga una perenne juventud con ardores tevolucionarios. Si esta nueva fe, como cualquier fe, le proporciona una mayor fuerza moral y un ejemplar espíritu de lucha, sus análisis políticos, en cambio, se resienten de una gtan simplicidad. En rigor, salta por encima 
de lo político, evaporándolo entre dos absolutos: antes la literatura, ahora la revolución.

A finales de los cuarenta, después de haber recortido todas las etapas del solipsismo, Sartre se perfilaba como un pensador capaz de reflexionar sobre la situación concreta del hombre en esta segunda mitad de siglo, sin escaparse por una ontología que ignorase la política. Su repentina conversión cierra las puertas a una ulterior reflexión política original. En ocasiones vamos incluso a pillarle repitiendo el discurso «revolucionario» de cualquier adolescente de clase media. En la forma concreta en que expresa su compromiso con el oprimido, podtá Sartre haberse salvado como persona, pero se condena como pensador. Quizá no andemos tan descarriados cuando sospechamos en toda conversión una claudicación intelectual. Se termina creyendo en Dios, en la Historia, en el Proletariado, qué más da, porque no se puede aguantar más el frío helador de un pensamiento lúcido. Sartre comunista resultaba ciertamente una contradicción difícil de digeris. Se explica que sus viejos amigos de los tiempos de la resistencia, Maurice Merleau-Ponty, Albert Camus, con este o aquuel motivo, terminasen rompiendo con él. Palabras huecas parecían ahora las críticas anteriores a la congelación estalinista del marxismo, el carácter sustancialmente burocrático del $\mathrm{PC}, \mathrm{la}$ necesidad de una vía democrática hacia el socialismo. El Saulo convertido en Paulo, en cuestiones estrictamente políticas, no tiene otta cosa que ofrecernos, que lo que es obvio en la izquierda, o lo que podríamos encontrar en cualquier catecismo revolucionario. En su apoyo incondicional a los movimientos de liberación nacional, ex su denuncia del colonialismo, en su rechazo de la intervención norteamericana en Vietnam, ¿quién, en la izquierda, no estaba de acuerdo con el? El problema era y sigue siendo el definir una estrategia socialista para la Europa desarrollada, y en este punto no basta la mejor voluntad revolucionaria.

La equivocación garrafal, me parece, consistió en suponer que, como ocurre en filosofía, en política también se avanza radicalizándose. Desde luego, en flosofía lo difícil y oportuno es el radicalismo: llegar hasta las raíces, tropezat con el fondo. El pensamiento, aun el que se pretende más radical, tiende a quedarse corto, dando todavía demasiado por sobreentendido. El error se descubre a menudo como falta de radicalidad por no haber ido suficientemente lejos. En cambio, el radicalismo en política en seguida topa con el límite en que se manifiesta su irracionalidad. En una situación objetivamente revolucionaria, oponer a la violencia del sistema la violencia de los oprimidos puede ser una dialéctica que funcione; pero en todas las demás ocasiones, que son las más frecuentes - la revolución es siempre la excepción-, la violencia de izquierdas manifiesta ptonto su irracionalidad al desenmascararse como complementaria y legitimadora de la violencia 
del sistema. En un determinado punto, la violencia de la extrema izquierda y de la extrema derecha acaban por converger, superando así su posible distinción. La violencia se revela al final como el atajo de los poderosos para salvaguardar sus intereses. Los caminos de los oprimidos son mucho más largos y dan muchísimas más vueltas. En filosofía una fuente de error suele ser la falta de radicalismo; en política, en cambio, el principio de cuanto más radical mejor nos arroja fuera de la política, en el horror que justamente la política quiere remediar: la lucha feroz de todos contra todos. La violencia es, asî, la forma de negación de la política que caracteriza a la derecha. En las condiciones de la Europa actual, predicar la acción violenta conlleva una forma de derechización.

En la evolución de Sartre cabe touy bien mostrar cómo su radicalización política se cortesponde con una mayor credulidad filosófica. Su decisión política de ponerse al servicio de los comunistas coincide, clato está, con su conversión al maxxismo - «la filosofía de nuestro tiempo, no superable porque las circunstancias que to han engendrado no han sido superadas》-; ponerlo en tela de juicio significaría retroceder a posiciones premarxistas. Radical en política, Sartre renuncia a serlo en filosofía, poniendo nada menos que puertas al campo, cercas a la flosofía. Si filosofar es siempre pelear con los límites -sociales, conceptuales, lingǘsticos-para saltarlos, admitir fronteras infranqueables es renunciar a pensar. Conceptos tan complejos y ambiguos como «lucha de clases», "plusvalor», «primacía de lo económico», le parecen diáfanos e indiscutibles. Sartre no tiene por qué referirse al pensamiento de Marx —apenas lo hace-, porque lo coloca más allá de lo discutible. Pensar nuestro tiempo exigiría hacetlo desde las coordenadas marxistas, tratando tan sólo de llenar los espacios vacíos. La filosofía antetior de Sartre, el existencialismo, dentro de las coordenadas marxistas, mantendría así su validez, al subrayar el carácter irreductible del individuo.

Su conversión no conlleva una desaprobación del pensamiento anterior, sino que, hegeliano ejemplar, lo absorbe en la siguiente etapa, como un momento necesario, aunque parcial. Sartre ha mantenido una identidad básica a través de sus diferentes etapas, convencido de que en cada período, medido con las circunstancias, dijo lo justo $\mathrm{y}$, en el fondo, siempre lo mismo: la determinación de lo humano como libertad y la pregunta por la realización concreta, personal y social de esta libertad. No conozco que se retractase de alguna idea o comportamiento -a no ser de su famosa $y$ harto pueril conferencia «El existencialismo es un humanismo» (1946)-, aunque, como auténtico intelectual, no dejase nunca de cuestionarse en bloque. Políticamente actuó, según su opinión, siempre como debió hacerlo, sin cuestionar siquiera su zigzagueante relación con los comunistas: distancianiento crítico después de 1945 -habian traicionado la revolución, 
colaborando por mandato soviético con la restauración de la vieja república burguesa-; adhesión en 1952 -al fin y al cabo, y con todos sus defectos, el Partido Comunista era el partido de la clase obrera, y apartarse de aquél era hacerlo del proletariado tedentor-; en fin, ruptura en 1956 -difícilmente se podía apoyar a un partido que en Hungría se colocaba al lado de los tanques, frente al pueblo.

Los años siguientes son tal vez los más difíciles y decisivos en la vida de Sartre: convertido al marxismo, no encuentra partido obrero en que militar. No tiene otra salida que sumergirse de nuevo en un esfuerzo titánico de reflexión y con un ritmo de trabajo impresionante intentar hacer inteligible la contradicción vivida: el marxismo podrá sex la filosofía de nuestro tiempo, pero la Historia parece marchar por otros andurriales. $\mathrm{Ni}$ en la Unión Soviética, que pretende haber realizado una revolución marxista, ni en Francia, donde el Partido Comunista es inconfundiblemente el partido marxista por antonomasia, la acción de estos dos sujetos históricos privilegiados puede considerarse liberadora y revolucionaria. ¿Acaso marxismo y libertad no son una y la misma cosa? Sartre se queda sin tierra bajo los pies, decidido a levantar de la nada su colosal Crítica de la Razón dialéctica (1960).

Aquellos años fueron también los de mi acercamiento al marxismo. A comienzos de los sesenta, ya instalado en Alemania, leo con deteximiento los escritos juveniles de Marx, el Marx hegeliano, subyugado por la temática que entonces nos acuciaba: la de la enajenación, que no es sino otra forma de plantear el problema de la libertad. El Capital, en cambio, tesultaba más diff́cil de roer, más por su novedad metodológica que por su dificultad intrínseca. Para gozar de $\mathrm{El}$ Capital hace falta sentirse en casa, tanto en la filosofía del idealismo alemán como en la economía inglesa. Por mi parte, había trabajado a Hegel, pero no a Ricardo. Mi faita de preparación me llevaba, según los días, a aceptar o techazar en bloque algunas de sus categorias fundamentales. Me resistía a reducir, como lo habían hecho algunos de mis amigos, la problemática científico-filosófica del mundo contemporáneo a una lectura correcta de El Capital. Me subleva el creyente, lector e intérprete de un solo libro. Sartre, con su Crítica..., me facilitó las cosas: antes de entrar en un estudio exhaustivo de $E l$ Capital, había que aclarar sus supuestos ontológicos. Ello me permitía, en el fondo, reducir el marxismo a un problema filosófico, es decir, huir del marxismo, como me reprochaban mis amigos marxistas.

Si, como proclamaba Sartre, «el marxismo es la Historia misma to mando conciencia de sí», de lo que se trata es de «experimentar, criticar y 
fundamentar en la Historia y en este momento del desatrollo de las sociedades humanas, los instrumentos de pensamiento por los que la Historia se piensa, en tanto que son también los instrumentos prácticos por los que se hace» (Critica..., pp. 134-135). Había que hacer inteligible ta Historia como un proceso global que totaliza cada una de las praxis individuales. Ia quimera racionalista no había llegado nunca a pretensión tan descomunal: en la cabeza de un hombre adquiría su razón fundamentante todo lo que ha sido, es y será en la Historia. Pues bien la Historia como totalidad y en cada una de sus infinitas totalizaciones, una vez hecha inteligible, diáfana, transparente, se revelaría marxista. El círculo dialéctico nos descubre al final lo que sabíamos desde el principio, pero en el grado sumo de la evidencia: el marxismo es la Historia misma tomando conciencia de sí.

Sartre fracasó, tenía que fracasar en el empeño. No cabe experimentar la Historia como totalidad totalizadora de todas y cada una de las praxis individuales, y el primer tomo de la Critica... se encamina, contra la voluntad del autor, a hacer plausible esta imposibilidad. Años más tarde, Sartre se excusa de no haber escrito el tevelador tomo segundo -el primero no constituye más que una propedéutica a la búsqueda de los conceptos básicos de interpretación--, aludiendo a la cantidad pavorosa de lecturas que hubiera tenido que echarse al coleto para obtener un conocimiento lo bastante preciso de la historia de la humanidad, como para hacerla inteligible como totalidad. No era la razón dialéctica la que fallaba, sino la contingencia individual, demasiados años, demasiado cansado. Para mí este fracaso tuvo muy saludables consecuencias: me libró de la tentación totalizadora de la dialéctica, poniéndome en sobreaviso sobre los peligros y las falacias de la filosofía de la historia.

Por fin podía leer El Capital como una de las obras cumbre de la literatura económica del siglo $\mathrm{XIX}$, purificado de cualquier tentación totalizadora. Catecúmeno marxista empecé a leer la Crítica de la Razón dialéctica con la esperanza de asistir a la fundamentación del marxismo como Ia ciencia misma de la Historia. Salí de sus páginas con el convencimiento de que la ciencia social empezaba allí donde se lograba superar cualquier residuo de filosofía de la historia, marxista o no marxista.

En 1975 defendiendo todavía categorías básicas del marxismo llega Sartre a resultados parecidos a los que llegué yo después de haber leído su Critica... y sobre todo después de haber estudiado con alguna atención el matxismo soviético, a saber que la condición para llegar a un verdadero socialismo es haber superado el marxismo. «Pienso que hay aspectos esenciales del marxismo que siguen válidos $[\ldots]$ pero estimo que hoy, como intento decirlo de algún modo en $S e$ tiene razón para rebelarse, es otro pensamiento el que se necesita, un pensamiento que tome en cuenta a un 
socialismo verdadero» (Situations [10], p. 193). Algo de esto ya barruntaba cuando, en 1952, se conviette al marxismo. La obra de esta última etapa ha recorrido un largo círculo para llegar al mismo punto, pero ya no como sospecha, sino como conocimiento. Sartre, al exigir una fundamentación ontológica del marxismo, nos ha ayudado a librarnos de él. Gracias también al esfuerzo realizado en la Crítica..., tenemos por fin clato que, en las condiciones de nuestro tiempo, avanzar hacia el socialismo supone superar el marxismo.

En el ambiente filosófico de la España de los cincuenta -escolástica en sus dos ramas, tomista y estalinista, más Ortega- Sartre parecía un filósofo de una llamativa originalidad y un valor inusitado para plantear las cuestiones cruciales de nuestro tiempo. Visto desde Alemania mostraba un aspecto muy distinto. No sólo resulta ya relativamente fácil identificar sus fuentes, Hegel, Marx, Nietzsche, Hussetl, Heidegger, sino sobre todo comprobar las diferencias cualitativas entre los originales germánicos y el epígono francés. Sartre se descubre como el buen divulgador de la filosofia alemana para el público latino y anglosajón. De $E l$ ser y la nada y de la Crítica..., tal vez lo que perdure más tiempo sean algunas de sus descripciones de considerable valor literario - la mirada, el pueblo de París al asalto de la Bastilla - peto rara vez encontraremos un concepto flosófico, una intuición que no pueda identificarse fácilmente, $o$ que no constituya un truismo traducido a un lenguaje técnico excesivamente complicado, expresado además en una retórica tan repititiva como pretenciosa. Con la facilidad del escritor torrencial, se puso a escribir densos y voluminosos tratados filosóficos de la misma manera que de niño novelas de aventuras. Nadie puede negatle, con la fantasía, el don de la imitación y de la palabra.

Sartre o la pasión de escribir - nos recuerda a los Hugo, los Dumas, los escritores de novelas por entregas- no es más que lo que escribe y mientras lo escribe. Su fuerza $\longrightarrow$ más bien su debilidad- proviene de la cantidad de géneros que cultiva: filosofía, teatro, novela, ensayo. En todos alcanza una altura considerable; en ninguno rompe la norma, topando con to excepcional. De su creación titeratia quedarán algunas obras menores -digo bien, obras menores; no se olvide que en este siglo escribieron James Joyce y Thomas Mann, para citar tan sólo dos antípodas-, como La nátusea y Las palabras; poco o nada de su teatro y algunos magníficos ensayos -Merleau-Ponty vivant- que también rozaron lo autobiográfico. El haber ocupado uno de los primeros puestos de su tiempo no es garantía de que la historia ratifique este veredicto: suele ocurtir lo contrario.

En cierto modo, Sartre es el Voltaire de nuestro siglo: la misma capa- 
cidad de síntesis y de vulgarización filosófica -en Voltaire, la filosofía inglesa, en Sartre Ia alemana-; el mismo don de sobresalir en los más diversos géneros, incluyendo la novela corta y el teatro; la misma disposición, muy francesa, de centrar en su persona el interés de la Europa de su tiempo, con el mismo afán denunciador de lo que se considera el mayor enemigo de la libertad -en Voltaire el clericalismo inquisitorial; en Sartre, el imperialismo colonialista y optesor. Comparar a Sartre con Voltaite implica a la vez un elogio - no cabe comprender el siglo $x x$ sin el primero, como tampoco el xvixi sin el segundo- que un prurito de poner las cosas en su sitio: si tuviéramos que nombrat a los filósofos o a los escritores verdaderamente importantes de estos dos siglos, no se nos ocurriría mencionar a Sartre ni a Voltaire. 